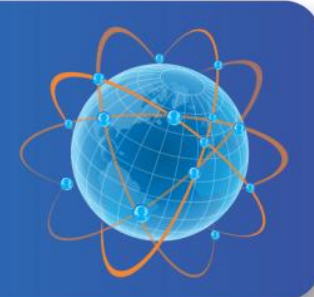

\title{
Fenomena Ojek Didalam Kampus Universitas Padjadjaran dan Relasi Sosial yang Terbangun di Dalamnya
}

Authors : Distyatami Lantri, Wahju Gunawan, Desi Yunita

Published by : Departemen of Sociology, Faculty of Social and Political Science, Universitas Padjadjaran

Accepted : March 2017; Approved : April 2017

Sosiogobal: Jurnal Pemikiran dan Penelitian Sosiologi is the Department of Sociology, Faculty of Social and Political Science, Universitas Padjadjaran flagship journal. The Sosioglobal journal founded in 2016 with the mission to publish original works of interest to the discipline of sociology in general, sociological thinking, new theoretical developments, results of research that enhance understanding of fundamental social processes, and methodological innovations. We are welcome a research article, working paper, theoretical/conceptual and methodological review to submit to our journal. In addition, we are accept relevant book review that currently publish and enrich sociological perspectives. Please submit article to http://jurnal.unpad.ac.id/sosioglobal

To cite this article :

Lantri, Distyatami, Wahju Gunawan and Desi Yunita.2017. Fenomena Ojek Didalam Kampus Universitas Padjadjaran dan Relasi Sosial yang Terbangun di Dalamnya.Sosioglobal : Jurnal Pemikiran dan Penelitian Sosiologi 1(2):132-142. 


\title{
FENOMENA OJEK DI DALAM KAMPUS UNIVERSITAS PADJADJARAN DAN RELASI SOSIAL YANG TERBANGUN DI DALAMNYA
}

\author{
Distyatami Lantri ${ }^{1}$, Wahju Gunawan ${ }^{2}$, Desi Yunita ${ }^{3}$ \\ 1. Prodi Sosiologi, Fakultas Ilmu Sosial dan Ilmu Politik, Universitas Padjadjaran \\ lantrid@gmail.com
}

\begin{abstract}
ABSTRAK
Penelitian ini ditujukan untuk menjelaskan relasi sosial pada kelompok ojek yang berada di dalam kampus Universitas Padjadjaran Jatinangor dengan melihat hubungan antar sesama ojek, kampus Universitas Padjadjaran dan hubungan yang terbangun antar sesama tukang ojek pangkalan tersebut. Pendekatan yang dipergunakan dalam penelitian ini adalah kualitatif, dimana penentuan informan dilakukan menggunakan teknik purposive. Adapun pengumpulan data dilakukan melalui observasi, wawancara, dan dokumentasi. Sedangkan untuk menguji validitas dan keabsahan data, dalam menganalisa data hasil penelitian tersebut, proses triangulasi data mutlak dilakukan. Hasil penelitian memperlihatkan bahwa relasi sosial yang terjalin antar sesama tukang ojek di pangkalan yang sama maupun dengan tukang ojek yang berbeda pangkalan memperlihatkan kecenderungan assosiatif dan dissosiatif. Meskipun begitu kecenderungan relasi sosial assosiatif lebih terlihat daripada dissosiatif. Adapun hubungan kelompok ojek yang ada di lingkungan kampus dengan kampus unpad sendiri juga menunjukkan relasi sosial yang dissosiatif.
\end{abstract}

Kata kunci: hubungan sosial, ojek, assosiatif dan dissosiatif

\begin{abstract}
This research aimed to explain the social relation on motorcycle taxi group (ojek) inside campus of Padjadjaran University in Jatinangor by looking the relationship between the motorcycle taxi, Padjadjaran University and the relationship built between fellow motorcycle taxi drivers. The approach used in this research is qualitative, where the determination of informants is using purposive technique. The data collected through observation, interview, and documentation. While to test the validity of data, in analyzing the data of the research, the data triangulation is absolutely done. The results of the study show that the social relationships that exist between motorcycle taxi drivers in the same base and the different motorcycle taxi bases show an associative and dissociative tendency. Yet the tendency of relative social relations is more visible than dissociative. The relationship of motorcycle taxi group in the campus environment with unpad campus itself also shows dissociative social relations.
\end{abstract}

Keywords : social relation, motorcycle taxi, associative and dissociative

\footnotetext{
2. Prodi Sosiologi, Fakultas Ilmu Sosial dan Ilmu Politik, Universitas Padjadjaran wahyu.gunawan@unpad.ac.id

3. Prodi Sosiologi, Fakultas Ilmu Sosial dan Ilmu Politik, Universitas Padjadjaran

desi.yunita@unpad.ac.id
} 


\section{PENDAHULUAN}

Sebagai kawasan terpadu pendidikan yang ditetapkan berdasarkan SK Gubernur bernomor 583/SK-PIK/1989, kawasan Jatinangor terus berkembang menjadi lingkungan yang padat penduduk. Sejak dikeluarkannya SK gubernur tersebut hingga saat ini diketahui telah ada empat universitas yang secara aktif melakukan aktivitas pendidikan dan pengajaran yaitu Universitas Padjadjaran, Institut Pemerintahan Dalam Negeri, Institut Teknologi Bandung, dan Institut Koperasi Indonesia. Dari keempat Perguruan Tinggi yang ada di wilayah Jatinangor tersebut universitas padjadjaran adalah universitas dengan jumlah mahasiswa paling banyak. Akan tetapi, banyaknya mahasiswa yang telah meningkatkan jumlah pemukiman kost di kawasan Jatinangor tersebut tidak di barengi dengan meningkatnya layanan transportasi. Hal tersebut pada akhirnya mendorong munculnya alternatif transportasi berupa ojek.

Kunarto dan Tabah (dalam Herukoco, 2003:1) mengatakan bahwa sebutan ojek adalah singkatan dari otto jegang, karena naik otto sambil mengangkang, sedangkan otto adalah sebutan lain dari sepeda motor pada tahun 60-an. Di Indonesia kendaraan sepeda motor kerap dijadikan alat transportasi seperti layak nya angkutan-angkutan umum. Dalam Kamus Besar Bahasa Indonesia ojek/ojék/ yaitu sepeda atau sepeda motor yang ditambangkan dengan cara memboncengkan penumpang atau penyewanya. Seperti yang dilansir oleh Viva.co.id (Adi Nugroho, 2015) ojek diperkirakan ada pertama kali sekitar tahun 1969-1970 di Jawa Tengah dan juga Jakarta. Awalnya kegiatan meng-ojek dilakukan menggunakan sepeda, namun seiring berjalannya waktu berubah menggunakan sepeda motor.

Aktivitas angkutan penumpang berupa ojek ini juga dapat ditemui di beberapa negara yang lain. Seperti di Vietnam yang menyebut ojek sebagai "xe om", "Habul-Habul' di Filipino, "Win" di Bangkok "Boda-Boda" di Uganda, "Okada" di Nigeria dan Ghana, serta "Zemidjan" di Benin dan Togo. Bahkan saat ini, seiring dengan berkembangnya teknologi informasi, ojek juga menjadi salah satu alternatif pekerjaan yang banyak menyerap pekerja. Hampir di setiap kota dan wilayah terdapat penyedia jasa ojek atau yang sering disebut dengan Tukang Ojek oleh masyarakat luas. Salah satunya adalah para penyedia ojek yang berada di lingkungan kampus Universitas Padjadjaran di Jatinangor. Kebutuhan akan transportasi juga dirasakan oleh mahasiswa, dosen, dan staf yang bekerja di lingkungan kampus Universitas Padjadjaran Jatinangor. Sehingga hal ini menyebabkan munculnya beberapa pangkalan ojek yang berada di dalam lingkungan kampus Unpad Jatinangor.

Adanya ojek yang bisa masuk ke dalam lingkungan kampus Universitas Padjadjaran Jatinangor memiliki kelebihan dan sekaligus kekurangan. Terbatasnya kemampuan fasilitas transportasi 
yang disediakan oleh kampus, telah menjadi celah yang dimanfaatkan dengan sangat baik oleh para pengojek, karena kemampuan aksesnya yang cepat dan fleksibel sehingga dapat menjangkau ketempat-tempat yang tidak dilewati oleh angkutan kampus. Selain dari adanya kelebihan tersebut, terdapat pula kekurangan dari ojek ini yaitu tidak adanya standar harga dan standar keamanan layanan, sehingga dengan padatnya lalu lintas mahasiswa yang menggunakan jasa ojek tersebut tidak jarang justru menjadi penyebab terjadinya kecelakaan.

Di lingkungan kampus Universitas Padjadjaran setidaknya telah diketahui ada lima pangkalan ojek, yaitu di gerbang lama atau gerbang bawah Universitas Padjadjaran, di depan Fakultas Ilmu Komunikasi, di depan Fakultas Kedokteran Gigi, dan di depan fakultas farmasi. Dari semua pangkalan ojek tersebut, pangkalan ojek yang berada di gerbang lama adalah pangkalan dengan jumlah pengojek terbanyak. Jika secara ekonomis, fenomena ojek tersebut telah memberikan pekerjaan bagi para penggiatnya, namun warga unpad lebih melihat semakin berkembangnya fenomena ojek tersebut sebagai suatu hal yang menimbulkan keresahan, karena selain mengganggu lalu lintas di dalam kampus dan menghilangkan estetika lingkungan kampus, kegiatan ojek di dalam kampus juga kerap menimbulkan kecelakaan-kecelakaan yang terjadi akibat dari kelalaian pengendara dan penumpang. Beberapa hal yang diuraikan tersebut adalah argumentasi ketertarikan penulis untuk mengetahui bagaimana hubungan sosial atau relasi sosial yang terjalin di antara tukang ojek yang ada di lingkungan kampus Universitas padjadjaran Jatinangor. Titik fokus dalam penelitian ini adalah mengetahui karakteristik dari kelompok-kelompok penyedia jasa ojek di kampus Unpad Jatinangor serta mengetahui interaksi yang terjalin antara penyedia jasa ojek di Kampus Unpad Jatinangor.

Sosiologi mengistilahkan hubungan antar sesama manusia sebagai relasi sosial, hubungan tersebut didahului dengan interaksi dan proses sosial (Taneko, 1990:109-110) proses sosial tersebut merupakan efek resiprokal yang terjadi dalam berbagai aspek kehidupan sepeti ekonomi, politik, hukum, dan lain sebagainya. Oleh karena itu dapat pula dikatakan bahwa interaksi sosial merupakan bentuk utama dari proses sosial.

Selanjutnya, interaksi sosial sebagai hubungan dinamis yang mempertemukan antar individu dan kelompok dibedakan menjadi dua jenis oleh Gofman (1963), yaitu focused interaction atau interaksi yang memiliki tujuan dan unfocused interaction atau interaksi yang tidak memiliki tujuan. Adapun bentuk-bentuk interaksi sosia tersebut dapat dibedakan menjadi; kerjasama, pertikaian, persaingan, dan akomodasi.

Penelitian mengenai Hubungan Sosial Ojek Kampus Unpad Jatinangor ini, menggunakan konsep hubungan sosial dalam perspektif sosiologi untuk melihat fenomena tersebut. Hubungan sosial dapat terbentuk dari hasil interaksi sosial yang telah terjalin lama dan 
memiliki pola yang berulang. Suatu kelompok yang telah terbentuk sejak lama, memiliki hubungan-hubungan sosial yang terjalin dengan berbagai pihak sehingga mereka dapat bertahan untuk waktu yang cukup lama. Ojek merupakan salah satu bentuk dari moda transportasi informal, dimana transportasi merupakan kebutuhan bagi masyarakat. Sehingga kebutuhan akan transportasi harus dipenuhi, baik dengan moda transportasi formal maupun informal.

Pangkalan-pangkalan ojek di dalam lingkungan kampus Unpad Jatinangor baik yang skalanya kecil dan skala besar telah ada sejak lama. Hubungan-hubungan yang mereka jalin juga telah berjalan dari awal mereka masuk ke dalam lingkungan kampus Unpad Jatinangor. Hubungan yang terjalin diantara tukang ojek dengan sesama tukang ojek karena adanya hubungan timbal balik dan saling memengaruhi serta dapat menghasilkan interaksi yang berbentuk assosiatif maupun dissosiatif. Berdasarkan penjelasan tersebut, maka dibangun suatu kerangka berpikir sebagai berikut:



Gambar 1. Relasi Sosial Kelompok Ojek

Gambar tersebut memperlihatkan bahwa hubungan sosial yang terbangun antar satu kelompok ojek dengan kelompok ojek lainnya bisa berbentuk assosiatif dan dissosiatif. Akan tetapi kesamaan pekerjaan dengan kesamaan tujuan untuk mendapatkan penghasilan dari menjadi tukang ojek telah membentuk pelaku ojek untuk lebih mengedepankan hubungan sosial assosiatif. Hal tersebut lebih terlihat karena kesamaan pekerjaan tersebut telah menuntut pengojek untuk menjadi bagian dari struktur yang lebih besar lagi yaitu institusi Universitas Padjadjaran. Dimana universitas padjadjaran sebagai lembaga pendidikan sangat mengedepankan keteraturan. Dan keteraturan tersebut hanya mungkin dapat dicapai jika ada kerjasama dan akomodasi dari seluruh elemen yang ada di dalammnya termasuk pula disitu tukang ojek. 


\section{METODE PENELITIAN}

Penelitian ini menggunakan pendekatan kualitatif dengan metode studi kasus. Dipilihnya metode studi kasus karena penelitian ini dilakukan secara intensif dan terinci mengenai aktivitas individu tukang ojek, dan kelompok ojek pangkalan dalam beraktivitas dan berinteraksi di dalam kampus universitas Padjadjaran. Pemilihan studi kasus sebagai metode karena penelitian tentang fenomena ojek di dalam kampus Universitas Padjadjaran ini lebih melihat tentang peristiwa yang saat ini sedang berlangsung atau aktual.

Lebih jauh lagi, metode kualitatif ini dipilih karena peneliti melihat bahwa kualitatif studi kasis adalah metode yang paling sesuai untuk meneliti hubungan sosial antara kelompok ojek di lingkungan Kampus Unpad Jatinangor. Adapun data yang dikumpulkan berupa data deskriptif berupa pengalaman subjek yang diteliti. Sehingga, data yang dikumpulkan lebih mengutamakan data langsung seperti wawancara, observasi, dan angket.

Selanjutnya, objek yang diteliti pada penelitian ini adalah hubungan sosial, yaitu hubungan sosial yang terjalin antara kelompok ojek di lingkungan Kampus Unpad Jatinangorserta hubungan sosial yang terbentuk dari hasil interaksi sosial, baik itu assosiatif maupun dissosiatif. Sedangkan yang menjadi subjek pada penelitian ini adalah kelompok-kelompok ojek yang ada di lingkungan kampus Unpad Jatinangor.

Pemilihan informan dilakukan secara acak namun mewakili tiap-tiap kelompok penyedia jasa ojek yang ada di lingkungan kampus Universitas Padjadjaran Jatinangor yang memahami informasi mengenai objek maupun subjek penelitian. Pemilihan informan ini lebih dititik beratkan pada kebutuhan untuk mendapatkan informasi yang mendalam mengenai objek dan subjek penelitian dari berbagai sudut pandang. Adapun beberapa aspek yang diteliti adalah; hubungan sosial antara dua orang atau lebih tukang ojek atau tingkat hubungan antar sesama tukang ojek baik individu maupun kelompok, hubungan kepercayaan, dan pola relasi yang terbangun.

Selain data primer yang merupakan hasil penelitian langsung lapangan, dikumpulkan pula data sekunder sebagai pendukung. Adapun infoman dalam penelitian ini ditentukan secara purposive, dengan kriteria sebagai berikut: (1) merupakan tukang ojek yang berada di lingkungan Unpad Jatinangor. (2) orang yang memiliki pengetahuan dan pemahaman mengenai tukang ojek yang ada di lingkungan Unpad Jatinangor. (3) orang yang memiliki pengetahuan mengenai sejarah perkembangan tukang ojek yang di lingkungan Unpad Jatinangor. 
Analisis data dilakukan dengan beberapa tahapan, yaitu data reduction, data display, dan conclusion drawing/verification. Data dianggap absah ketika telah melalui beberapa tahapan pengolahan dan triangulasi, seperti; Membandingkan data hasil pengamatan dengan data hasil wawancara. Membandingkan apa yang dikatakan orang di depan umum dengan apa yang dikatakannya secara pribadi. Membandingkan apa yang dikatakan orang-orang tentang situasi penelitian dengan apa yang dikatakannya sepanjang waktu. Membandingkan keadaan dan perspektif seseorang dengan berbagai pendapat dan pendangan orang seperti rakyat biasa, orang yang berpendidikan menengah atau tinggi, orang berada, orang pemerintahan. Membandingkan hasil wawancara dengan isi suatu dokumen yang berkaitan.

\section{KERANGKA TEORI/KONSEP}

\section{Relasi Sosial Assosiatif}

Relasi sosial lebih sering dimaknai sebagai hubungan antara sesama manusia, hubungan tersebut terjadi karena adanya interaksi dan proses sosial atau suatu pengaruh resiprokal dari berbagai aspek kehidupan dalam masyarakat seperti ekonomi, politik, hukum dan lain sebagainya. Interaksi sosial sendiri merupakan suatu hubungan dinamis yang memungkinkan seseorang atau sekelompok orang untuk saling bertemu dalam suatu hubungan sosial.

Penelitian ini dalam prosesnya memperlihatkan bagaimana relasi sosial antar kelompok ojek di lingkungan kampus Unpad Jatinangor tersebut terjadi, dan merujuk pada bentuk umum dari relasi sosial yang dikatakan beberapa ahli yaitu assosiatif dan dissosiatif yang mana di dalam bentuk umum tersebut terdapat beberapa bentuk khusus seperti kerjasama, dan akomodasi.

\section{Kerjasama}

Bentuk kerjasama yang dominan terlihat pada kelompok ojek adalah upaya antar kelompok untuk saling mematuhi kesepakatan yang terbangun diantara sesama pangkalan ojek dalam rangka untuk menjaga keharmonisan dan menghindari munculnya pertikaian. Menjaga keamanan ketertiban dan keharmonisan lingkungan Universitas Padjadjaran mutlak menjadi tanggung jawab mereka, karena jika hal tersebut tidak terjaga maka tentunya para tukang ojek tersebut sebagai penyedia jasa akan dirugikan sendiri. Bentuk kerjasama dalam menjaga ketertiban dan keharmonisan tersebut meskipun tidak tertulis, namun telah menjadi kesepakan umum yang dipatuhi oleh semua pelaku ojek, sehingga jika terjadi pelanggaran oleh pengojek maka secara spontan semua pengojek baik itu yang berasal dari satu pangkalan maupun dari pangkalan yang berbeda sesegera mungkin menegur dan mengingatkan. 
Aturan tidak tertulis tersebut salah satunya adalah mengenai ojek untuk tidak mengambil muatan atau penumpang di wilayah orang lain. Hal tersebut juga menjadi salah satu alasan bagi para penyedia jasa ojek untuk saling menghormati pangkalan ojek satu sama lain, guna menghindari pertikaian. Bentuk kerjasama lainnya yang juga terlihat adalah adanya pemungutan iuran harian sebesar 2000 rupiah bagi setiap tukang ojek dimana uang tersebut dipergunakan untuk biaya pengobatan jika terjadi kecelakaan, ataupun acara-acara mendadak yang dilakukan oleh anggota ojek dalam kelompok pangkalan yang ada di gerbang lama. Adanya upaya untuk melakukan pungutan memperlihatkan bahwa kelompok ojek tersebut ingin menciptakan keteraturan sekaligus jaminan pribadi dalam kelompok.

Selanjutnya, adanya kerjasama antar sesama pengojek yang berbeda pangkalan tersebut juga telah mendorong perubahan perilaku pengojek, dimana jika dulu setiap pengojek dapat mengangkut penumpang pergi-pulang, sekarang mereka hanya dapat mengakut penumpang satu rute saja yaitu pergi atau pulang saja. Hal tersebut terjadi karena dimasing-masing fakultas sudah ada tukang ojek lainnya yang ngetem.

\section{Akomodasi}

Sedangkan bentuk akomodasi yang diperlihatkan oleh para pengojek yang ada dilingkungan kampus Unpad adalah dengan selalu mengedepankan cara-cara damai dan kekeluargaan, dimana setiap masalah selalu diusahakan untuk diselesaikan secara informal antar sesama pengojek. Selanjutnya, selain ada upaya-upaya yang dilakukan untuk menyelesaikan pertikan, terdapat pula upaya-upaya untuk mencegah agar tidak terjadi pertikaian atau gesekan antar sesama pangkalan ojek maupun antar sesama anggota ojek dalam satu pangkalan. Sehingga dapat dikatakan adanya akomodasi yang terjadi diantara kelompok-kelompok ojek di lingkungan kampus Unpad Jatinangor.

\section{Relasi Sosial Dissosiatif}

Relasi sosial dissosiatif dimaknai sebagai suatu bentuk pertikaian dan persaingan. Meskipun pertikaian bukan sesuatu yang umum terjadi antar sesama pengojek namun munculnya pertikaian tersebut umumnya terjadi karena ada pengojek yang melanggar kesepakatan atau bersikap berlebihan ketika berguyon.

Adapun pertikaian, umumnya terjadi karena adanya perebutan penumpang antara satu pangkalan dengan pangkalan oleh yang lain. Seperti telah diuraikan sebelumnya, bahwa tiaptiap kelompok ojek telah memiliki pangkalan ojek masing-masing dan wilayah angkut muatan sesuai dengan pangkalan ojek mereka. Namun, meskipun begitu masih kerap terjadi gesekan diantara kelompok ojek yang telah lama berada di lingkungan kampus dengan kelompok 
ataupun individu-individu yang berasal dari luar kampus lalu menetap ataupun mengetem di lingkungan kampus dan dianggap "mengambil”" muatan ojek-ojek yang berada di kampus.

Oleh karena itu maka, jika dicermati akan terlihat bahwa dalam dunia ojek, terdapat beberapa tata aturan yang harus diketahui serta dipahami dan ditaati oleh para penyedia jasa ojek pangkalan, tata aturan tersebut adalah dilarang untuk mengambil muatan atau penumpang di wilayah ojek pangkalan lain, apabila mengantar muatan, harus kembali dengan muatan kosong, apabila penyedia jasa ojek membawa muatan dari wilayah ojek lain, hal tersebut dianggap tidak menghargai sesama penyedia jasa ojek dan memicu pertikaian.

Jika dilihat dari aspek persaingan, hal tersebut sebenarnya tidak terlalu terlihat karena persaingan terjadi berdasarkan sistem antrean yang telah digunakan selama ini. Sehingga siapa saja pengojek yang datang lebih dahulu dipangkalan maka mereka akan dapat muatan lebih dahulu. Sehingga dapat pula dikatakan bahwa semakin rajin untuk bangun pagi, maka semakin besar peluang pengojek untuk mendapatkan penghasilan yang lebih besar.

Uraian tersebut memperlihatkan bahwa adanya hubungan sosial assosiatif karena terjadi kerja sama dan akomodasi diantara sesama kelompok ojek, serta kampus unpad yang mana lingkungan kampus ini menjadi tempat beroperasinya ojek tersebut. Meskipun hubungan dengan kampus Unpad baru terjalin, namun telah tampak adanya timbal balik dan saling mempengaruhi diantara keduanya. Selain dari hubungan sosial asosiatif, terdapat pula hubungan sosial yang bersifat dissosiatif karena terjadi persaingan dan pertikaian diantara sesama kelompok ojek di lingkungan kampus Unpad Jatinangor. Hubungan sosial yang bersifat dissosiatif khususnya pertikaian ini tidak memiliki rentan waktu yang panjang, karena terjadi apabila ada kesalah pahaman diantara kedua belah pihak. Namun, apabila persaingan terjadi selama kedua belah pihak masih ada dan masih memiliki tujuan yang sama, yaitu menarik minat penumpang demi pemenuhan kebutuhan ekonomi. Sehingga hubungan sosial yang terjadi cenderung pada hubungan sosial assosiatif.

Beroperasinya ojek di dalam kampus dapat dilihat sebagai bentuk kepedulian Universitas Padjadjaran terhadap lingkungan sekitar dengan memberikan kesempatan masyarakat disekitarnya untuk mendapatkan kesempatan berusaha salah satunya adalah dengan menjadi penyedia transportasi ojek. Namun meskipun begitu, sebagai institusi pendidikan unpad juga membuat aturan-aturan berkaitan dengan keberadaan ojek tersebut sehingga keberadaannya tidak mengganggu aktivitas pendidikan. Selain dari adanya aturan-aturan yang harus dipatuhi oleh para pelaku ojek dari Universitas Padjadajaran, antar sesama pelaku ojek untuk 
menghindari adanya gesekan atau konflik akibat persaingan dalam memperebutkan penumpang, maka sesama pengojek juga memiliki aturan tidak tertulis yang disepekati oleh semua pengojek.

Munculnya kesepakatan bersama yang terbangun antar kelompok pengojek yang akhirnya disepakati oleh semua individu pengojek menunjukkan bahwa ojek yang ada di sekitar kampus Universitas Padjadjaran dapat pula dilihat sebagai suatu bangunan sistem sosial meskipun skalanya sangat kecil. Namun adanya aturan yang dibuat oleh Universitas Padjadjaran sebagai sebuah institusi telah mendorong adanya penyesuaian-penyesuaian dalam aktivitas pengojek. Hal tersebut secara jelas memperlihatkan bahwa ojek juga melakukan adaptasi. Sebagai sebuah sistem tujuan adanya kelompok pengojek adalah untuk memperoleh penghasilan secara ekonomi dengan menyediakan jasa transportasi motor. Adanya tujuan untuk memperoleh penghasilan secara ekonomi ini telah mendorong terbentuknya pola perawatan sistem yang ada dan dikembangkan tersebut. Sehingga antar kelompok pengojek dengan kelompok pengojek yang lain kondisi harmonis tetap terjaga dimana hal tersebut menciptakan iklim ekonomi yang baik bagi semua orang. Pola-pola interaksi yang telah terbangun dengan adanya konsensus atau kesepakatan sosial tersebut harus terus dijaga dan diperbaharui seiring dengan perkembangan kondisi sosial yang melingkupinya.

Ojek sebagai kelompok eksternal dari kampus Unpad tidak secara serta merta dapat dihilangkan. Akan tetapi, kondisi sosial yang ada sekarang juga menuntut pelaku ojek untuk melakukan perubahan-perubahan seiring dengan terjadinya perubahan kondisi sosial di masyarakat. Fenomena ojek online, mahasiswa yang merangkap menjadi tukang ojek bagi teman-temannya, adalah dua hal yang menjadi ancaman eksistensi ojek itu sendiri. Di sisi lain, keenganan ojek untuk memperbaiki standar pelayanan, penyeragaman harga, dan tidak adanya standar operasional yang baku, membuat lambat laun ojek menjadi kurang diminati. Dengan begitu dapat dilihat bahwa meskipun terlihat sebagai suatu bangunan yang saling menguatkan antar satu dengan yang lainnya, namun ojek tersebut sesungguhnya merupakan suatu kesatuan yang cair. Sehingga sangat mungkin untuk hancur jika pengojek tersebut tidak mau menyesuaikan diri pada kondisi-kondisi sosial baru yang saat ini berkembang.

\section{SIMPULAN}

Relasi sosial yang berkembang pada komunitas ojek yang ada di kampus unpad jatinangor telah telah menciptakan suatu karakteristik yang unik. Hal tersebut terjadi karena antara satu kelompok dengan kelompok yang lainnya telah menunjukkan saling memiliki ketergantungan. 
Akan tetapi, meskipun begitu, setidaknya ada beberapa hal yang dapat disimpulkan yaitu sebagai berikut:

1) Agar kerjasama dapat terjalin dalam waktu yang lama, selain adanya system antrean juga diperlukan suatu standarisasi pelayanan, apakah itu harga, aturan main, dan rute.

2) Unpad sebagai lembaga yang memiliki aturan, haruslah mendorong para pelaku ojek yang ada di dalam kampus untuk ikut aturan main yang ada di unpad, salah satunya adalah mengenai rute transportasi, karena sering kali para pengojek yang menjadi pelopor dilanggarnya aturan berkendara di dalam kampus.

3) Pengojek harus memiliki standari prosedur pelayanan yang menyesuaikan dengan kampus, jika pertikaian, persaingan maupun bentuk gesekan-gesekan yang terjadi tersebut umumnya terjadi antara sesama pengojek maka Unpad sebagai tempat berlangsungnya aktivitas mengojek tersebut juga harus menunjukkan ketegasan terhadap aturan main yang harus dipatuhi jika pengojek tersebut masih tetap ingin bertahan.

\section{DAFTAR PUSTAKA}

Gillin, dan Gillin Cultural Sociology, a revision of An Introduction to Sociology, New York: The Macmillan Company, 1954.

Moleong, Lexy J. Metode Penelitian Kualitatif, Bandung: PT Remaja Rosdakarya, 2014

Sugiyono, Metode Penelitian Kuantitatif Kualitatif dan R\&D, Bandung: Alfabeta, 2012.

Taneko, Soleman b., Struktur dan Proses Sosial: Suatu Pengantar Sosiologi Pembangunan, Jakarta: Rajawali, 1990.

Astuti, Sugi. Pola Relasi Sosial dengan Burub Tani dalam Produksi Pertanian (Studi Deskriptif Masyarakat di Desa Tanjung Rejo, Kecamatan Percut Sei Tuan, Kabupaten Deli Serdang, Skripsi S1 Universitas Sumatera Utara, Medan, 2012. Melalui: http:// repository.usu.ac.id

Bardis, Panos D. Social Interaction and Social Processes, Reprinted from the International Behavioural Scientist, December 1978, pp. 7-32

CDIA, Informal Public Transportation Networks in Three Indonesian Cities, Juni 2011.

Fahmi, Khairul. Deskripsi Pola Pengoperasian dan Penggunaan Angkutan Umum Informal di Kota Pasir Pengaraian, Jurnal APTEK, Vol. 4, No. 1, Januari 2012. Melalui: http:/ / download.portalgaruda.org [24/5/16]

Handayani, Dewi. dkk, Analisis Kelayakan Finansial Operasional Pelayanan Ojek di Perkotaan di Indonesia untuk. Menjawab Prospek Keberbasilan Moda Paratransit Sepda Motor di Masa Mendatang (Studi Kasus di Kota Surakarta-Jawa Tengah), Jurnal Dinamika Teknik Sipil, Vol. 11, No. 2, Mei 2011. Melalui: https://publikasiilmiah.ums.ac.id [24/5/16]

Handayani, Dewi. Indrasurya B Mochtar, Ria AA Soemitro, Karakteristike Alat Transportasi Informal Ojek Sepeda Motor di Perkotaan (studi Kasus Kota Surakarta), Seminar Nasional Pascasarjana IX-ITS, Surabaya 12 Agustus 2009. Melalui: https://kaisnet.files.wordpress.com [24/5/16] 
Herukoco, Penertiban Tukang Ojek dengan Sepeda Motor Ilegal di Polres Sukabumi, Pascasarjana-UI, 2003

Isfanari, Harnen Sulistio, Achmad Wicaksono, Kajian Karakteristik Angkutan Ojek Sepeda Motor dan Cimodo di Kota Mataram, Jurnal Rekayasa Sipil, Volume 5, No. 2 ,2011. Melalui: http://rekayasasipil.ub.ac.id [ 8/6/16]

Junita, Erna. Hubungan Sosial-ekonomi Persatuan Ojek. Nagari Tambangan di Kecamaran X Koto Kabupaten Tanah Datar. Jom FISIP Vol. 2 No.1 (2015). Melalui: http://jom.unri.ac.id [6/10/15]

Ritzer, George. Douglas J. Goodman. 2004. Teori Sosiologi Modern. Edisi Keenam. Prenada Media. Jakarta

Shantyabudi, Firman. Tukang Ojek dan Interaksi Sosial, Tesis Megister-Universitas Indonesia, Jakarta 2000. Melalui: http://lib.ui.ac.id

Suryadi. Tukang Ojek, Studi Tentang Perilaku Berlalulintas di Wilayahh Perumnas Antang, Makasar. Skripsi Universitas Hasanudin Makasar (2012)

Sr Maries V L, B A Sociology introduction to Sociology, University of Calicut School of Distance Education, india 2014.

Tatum, Evipania Suryantika, Bentuk. Hubungan Sosial dalam Komunitas Blogger di Internet (studi Deskripsi terbadap Mahasiswa Perguruan Tinggi yang Menjadi Anggota Komunitas Blogger dalam situs Blogfam.com). S1 Thesis, UAJY. 2010. Melalui: http:/ /e-journal.uajy.ac.id [12/6/16]

Tikara, Krisna Surya. I Made Suraharta, Hotland Silaban, Analisis Faktor Pemiliban Moda Angkutan Informal (Taksi Gelap) dan Kebutuhan Angkutan Taksi di Kabupaten Minahasa Selatan, The 18th FSTPT International Symposium, Unila, Bandar Lampung, August 28, 2015. Melalui: http://eng.unila.ac.id [15/5/16] 